\title{
Análise físico-química da qualidade da água do rio Itapecuru no município de Caxias-MA
}

\author{
Physical-chemical analysis of the water quality of the Itapecuru River in the municipality of \\ Caxias-MA \\ Análisis físico-químico de la calidad del agua del río Itapecuru en el municipio de Caxias-MA
}

Recebido: 18/10/2021 | Revisado: 27/10/2021 | Aceito: 24/11/2021 | Publicado: 03/12/2021

\author{
Luciana Rocha Paula \\ ORCID: https://orcid.org/0000-0002-6264-7876 \\ Universidade Estadual do Maranhão, Brasil \\ E-mail: lucianapaula_99@hotmail.com \\ Kellyane Karen Ferreira Aguiar Cesar \\ ORCID: https://orcid.org/0000-0002-4635-2410 \\ Universidade Estadual do Maranhão, Brasil \\ E-mail: kellyanekaren@outlook.com \\ Anny Karoline Rodrigues Batista \\ ORCID: https://orcid.org/0000-0001-9482-6679 \\ Universidade Estadual do Maranhão, Brasil \\ E-mail: karol_rodrigues.b@ hotmail.com \\ Francisléia Falcão França Santos Siqueira \\ ORCID: https://orcid.org/0000-0001-7021-3640 \\ Universidade Estadual do Maranhão, Brasil \\ E-mail: leiafalcao7@gmail.com \\ Letícia da Silva \\ ORCID: https://orcid.org/0000-0002-1514-255X \\ Universidade Estadual do Maranhão, Brasil \\ E-mail: 1sleticiasilva@ hotmail.com \\ Daniel Limeira Filho \\ ORCID: https://orcid.org/0000-0001-9377-9516 \\ Universidade Estadual do Maranhão, Brasil \\ E-mail: limeira84@hotmail.com \\ Maria Fernanda Ribeiro Ferreira \\ ORCID: https://orcid.org/0000-0002-6292-8539 \\ Universidade Estadual do Maranhão, Brasil \\ E-mail: mf035476@gmail.com \\ Maria Aparecida de Gois Almeida \\ ORCID: https://orcid.org/ 0000-0003-4415-3255 \\ Universidade Estadual do Maranhão, Brasil \\ E-mail: cidagoesma@hotmail.com \\ Leonardo Andrade Gomes Nunes \\ ORCID: https://orcid.org/0000-0002-8239-0641 \\ E-mail: leonardoandrade941@gmail.com \\ João da Paixão Soares \\ ORCID: https://orcid.org/0000-0001-9792-1161 \\ E-mail: jpsoares@ifma.edu.br \\ Carlos Augusto Silva de Azevedo \\ ORCID: https://orcid.org/0000.0002.0503.3843 \\ Universidade Estadual do Maranhão, Brasil \\ E-mail: casazevedo08@gmail.com \\ Francisco Laurindo da Silva \\ ORCID: https://orcid.org/0000-0001-6837-4509 \\ Universidade Estadual do Maranhão, Brasil \\ E-mail: flspb@yahoo.com.br
} Instituto Federal de Educação, Ciência e Tecnologia do Maranhão, Brasil Instituto Federal de Educação, Ciência e Tecnologia do Maranhão, Brasil

\section{Resumo}

O rio Itapecuru passou por intensos processos de degradação ambiental, devido a algumas interferências irregulares de ações antrópicas, bem como, declínio da vegetação ripária, dentre outras ações que estão causando danos ao meio ambiente e a saúde da população que utiliza essa água para diversos fins como: balneabilidade, atividades de pesca, irrigação de plantas dentre outros. Este trabalho foi desenvolvido com o objetivo de analisar em termos de parâmetros 
físico-químicos a qualidade da água do rio Itapecuru no município de Caxias-MA. Tratou-se de um estudo de natureza experimental, com abordagem quanti-qualitativa, realizado no período de 22 de julho a 08 de setembro ano de 2021. As coletas foram obtidas em 10 pontos. Os parâmetros analisados foram: temperatura da água, condutividade elétrica, potencial hidrogeniônico $(\mathrm{pH})$ e oxigênio dissolvido (O.D.). A temperatura média dos pontos foi de $26,8^{\circ} \mathrm{C}$. $\mathrm{Na}$ condutividade a maior média encontrada foi de $60,57 \mu \mathrm{S} / \mathrm{cm}$, e a menor média foi de $32,47 \mu \mathrm{S} / \mathrm{cm}$. No potencial hidrogeniônico a média mais elevada foi de 7,6 e a menor apresentou 6,7. No que se refere ao oxigênio dissolvido, à maior média foi de $10,47 \mathrm{mg} / \mathrm{L}$ e a menor média de $5,23 \mathrm{mg} / \mathrm{L}$. Conforme os dados obtidos na presente pesquisa a temperatura apresentou valores acima do limite permitido para Classe 2 segundo o Programa Nacional de Avaliação da Qualidade das Águas (PNQA) e os parâmetros condutividade, pH e O.D. se enquadraram dentro dos padrões da legislação vigente.

Palavras-chave: Rio Itapecuru; Qualidade da água; Físico-química.

\begin{abstract}
The Itapecuru River has undergone intense processes of environmental degradation, due to some irregular interference of anthropic actions, as well as decline of riparian vegetation, among other actions that are causing damage to the environment and the health of the population that uses this water for various purposes such as: bathing, fishing activities, irrigation plants among others. This work was developed with the aim of analyzing the physical-chemical parameters of the water quality of the Itapecuru River in the municipality of Caxias-MA. It was a study of experimental nature, with quanti-qualitative approach, performed in the period from July 22 to September 8, 2021. The collections were obtained in 10 points. The parameters analyzed were: water temperature, electrical conductivity, hydrogen potential $(\mathrm{pH})$ and dissolved oxygen (O.D.). The average temperature of the points was $26.8^{\circ} \mathrm{C}$. The highest mean conductivity was $60.57 \mu \mathrm{S} / \mathrm{cm}$ and the lowest mean was $32.47 \mu \mathrm{S} / \mathrm{cm}$. In the hydrogen potential, the highest average was 7.6 and the lowest was 6.7. Regarding dissolved oxygen, the highest average was $10.47 \mathrm{mg} / \mathrm{L}$ and the lowest average was $5.23 \mathrm{mg} / \mathrm{L}$. According to the data obtained in this research the temperature showed values above the limit allowed for Class 2 according to the National Program for the Evaluation of Water Quality (PNQA) and the conductivity, $\mathrm{pH}$ and O.D. parameters were within the standards of the current legislation.
\end{abstract}

Keywords: Itapecuru River; Water quality; Physical-chemical.

\title{
Resumen
}

El río Itapecuru ha sufrido intensos procesos de degradación ambiental, debido a algunas interferencias irregulares de acciones antrópicas, así como a la disminución de la vegetación ribereña, entre otras acciones que están causando daños al medio ambiente y a la salud de la población que utiliza esta agua para diversos fines como: baño, actividades de pesca, plantas de riego entre otros. Este trabajo se desarrolló con el objetivo de analizar los parámetros físicoquímicos de la calidad del agua del río Itapecuru en el municipio de Caxias-MA. Se trata de un estudio de carácter experimental, con enfoque cuanti-cualitativo, realizado en el periodo comprendido entre el 22 de julio y el 8 de septiembre de 2021. Las colecciones se obtuvieron en 10 puntos. Los parámetros analizados fueron: temperatura del agua, conductividad eléctrica, potencial de hidrógeno $(\mathrm{pH})$ y oxígeno disuelto (OD). La temperatura media de los puntos fue de $26,8^{\circ} \mathrm{C}$. La conductividad media más alta fue de $60,57 \mu \mathrm{S} / \mathrm{cm}$ y la media más baja de $32,47 \mu \mathrm{S} / \mathrm{cm}$. En el potencial de hidrógeno, la media más alta fue de 7,6 y la más baja de 6,7. En cuanto al oxígeno disuelto, la media más alta fue de $10,47 \mathrm{mg} / \mathrm{L}$ y la más baja de $5,23 \mathrm{mg} / \mathrm{L}$. De acuerdo con los datos obtenidos en esta investigación la temperatura presentó valores por encima del límite permitido para la Clase 2 según el Programa Nacional de Evaluación de la Calidad del Agua (PNQA) y los parámetros de conductividad, pH y D.O. estuvieron dentro de los estándares de la legislación vigente.

Palabras clave: Río Itapecuru; Calidad del agua; Físico-químico.

\section{Introdução}

A água é essencial para a vida, sendo assim recurso natural primordial para os seres vivos, além de ser fundamental aos ecossistemas (Bacci \& Pataca, 2008; Brasil, 2018; Ridder Vieira, Costa \& Barrêto, 2006; Silva et al., 2019). As ações humanas, voltadas para a economia ou não, necessitam de recursos hídricos para a fabricação industrial, produção de energia, agropecuária, agricultura, segurança, entretenimento, alimentos e higiene (Agência Nacional de Águas [ANA], 2019; Bicudo, Tundisi \& Scheuenstuhl, 2010; Saneamento, 2018; Souza et al., 2014). Ela é necessária no consumo humano, e a diversidade de sua utilização reflete em atividades socioeconômicas, na promoção da saúde, na qualidade de vida e no desenvolvimento populacional (Costa et al., 2012; Silva, Alencar Carvalho \& Cardoso, 2019; Tundisi, 2014).

Da quantidade total de água disponível no planeta, 97\% corresponde a água salgada e apenas 3\% a água doce. Destes, 2,5\% estão congeladas na Antártica, no Ártico e em geleiras, não disponíveis para uso humano. Somente uma parcela de $0,5 \%$ 
representa a água doce acessível para humanidade, encontrando-se sob a forma de chuvas, armazenada em aquíferos, lagos naturais, reservatórios e rios (ANA, 2019; Bicudo, Tundisi \& Scheuenstuhl, 2010; Tardoque, 2021). Os recursos hídricos superficiais gerados no Brasil representam 50\% do total dos recursos da América do Sul (Tucci, Hespanhol \& Cordeiro Netto, 2001) e aproximadamente 12\% dos recursos mundiais (Costa et al., 2012; Tundisi, 2014), distribuídos da seguinte forma: $70 \%$ estão na Região Norte, um pouco acima de $15 \%$ no Centro-Oeste, $12,3 \%$ no Sul e Sudeste e na Região Nordeste apenas 2,7\% (Galvão Junior, Custódio \& Duarte, 2018; Gomes, 2019).

Os rios são considerados principal fonte de água potável e importante recurso de água doce, sendo a água doce considerada fonte indispensável para a vida dos seres vivos de diversos ambientes (Al-Aboodi, Abbas \& Ibrahim, 2018). Além da disponibilidade de água superficial garantida pela vazão de rios e pelos reservatórios estima-se que a disponibilidade de água subterrânea no Brasil seja em torno de 14.650 m³/s (ANA, 2019). Na última década, a degradação generalizada da qualidade da água em sistemas hídricos tem sido provocada pelo rápido desenvolvimento das indústrias, agricultura e urbanização (Al-Aboodi, Abbas \& Ibrahim, 2018; Dellamatrice \& Monteiro, 2014; Mello \& Olivo, 2016; Silva Pereira, 2004; Sodré, 2012). Nesse contexto, a continuidade da qualidade dos recursos hídricos depende da contribuição da sociedade humana como um todo, no sentido de valorização, preservação e conservação desses recursos (Costa et al., 2012; Venancio et al., 2015).

O sistema hidrológico dos rios e sua qualidade estão sujeitos a mudanças contínuas devido à construção de barragens, reservatórios e estruturas industriais. As condições locais predominantes, como o clima e a qualidade das rochas, levam a uma mudança na qualidade da água de uma região para outra (Feio \& Teixeira, 2019). A qualidade da água de superfície tornou-se uma questão importante e sensível em muitos países, devido à preocupação de que a água doce será um recurso escasso no futuro (Silva, Alencar Carvalho \& Cardoso, 2019). Neste contexto, os programas de monitoramento da água nos sistemas hídricos desempenham um papel importante, pois é necessário determinar o grau de contaminação e o efeito da qualidade no seu uso para diferentes fins (Al-Aboodi, Abbas \& Ibrahim, 2018).

A qualidade da água pode ser mensurada por meio de vários parâmetros com relevância sanitária (de origem natural ou antropogênica), que demonstram as suas características fundamentais, sendo elas físicas, químicas e biológicas. No Brasil, os padrões de qualidade dos corpos d'água são estabelecidos pela Resolução do Conselho Nacional do Meio Ambiente $\mathrm{n}^{\circ} 357$ e suas modificações, onde se encontram classificados conforme seu tipo de utilização e destino, já a gestão de recursos hídricos tem se fundamentado na Política Nacional de Recursos Hídricos (PNRH) (Brasil, 1997,2005; Von Sperling, 2005).

No Brasil, houve um aumento da intensidade da degradação dos rios urbanos, o que caracteriza a grande importância da monitoração das variáveis da qualidade da água (Al-Aboodi, Abbas \& Ibrahim, 2018; Carvalho, Marangon \& Santos, 2020). Das cinco regiões brasileiras, o Nordeste possui um nível reduzido de informações a respeito das vazões dos corpos d'água e é quase inexistente a disponibilidade de dados sobre a qualidade das águas superficiais das bacias hidrográficas inseridas nesta região do país (Medeiros, Silva \& Lins, 2018). No Estado do Maranhão esse instrumento de gestão de recursos hídricos, ainda não é realizado de maneira satisfatória (Martins, 2019). Vale ressaltar que ele é um dos Estados brasileiros ricos em bacias hidrográficas de grandes dimensões e seus rios se distinguem por serem permanentes e manterem grande volume de água durante todo o ano (Feitosa \& Almeida, 2002).

A bacia hidrográfica do rio Itapecuru destaca-se como a mais importante na Região Hidrográfica Atlântico Nordeste Ocidental. Seu rio principal nasce dentro do Parque Estadual do Mirador, perpassa uma extensão de $1.050 \mathrm{~km}$ até a sua foz na baía do Arraial, que fica localizada ao sul da Ilha de São Luís, por meio de duas vias de rios denominados de Tucha e Mojó. No Maranhão, aproximadamente três milhões de pessoas, em 52 cidades dependem desse manancial (Alcântara, 2004; Alves, 2010; Brasil, 2006; Companhia de Desenvolvimento dos Vales do São Francisco e do Parnaíba [CODEVASF], 2019). 
O vale do Itapecuru abrange uma área de $53.216,84 \mathrm{~km}^{2}$, o que equivale a $16,03 \%$ do estado do Maranhão e o torna a segunda maior bacia fluvial do território maranhense. Encontra-se classificada em três regiões fisiográficas: Alto, Médio e Baixo Itapecuru, compreendendo oito amplos afluentes em sua margem direita, ressaltando-se os rios Pirapemas e Itapecuruzinho e os córregos Seco, do Ouro, Gameleira, Cachimbo e Guariba (Alcântara, 2004; Alves, 2010; Núcleo Geoambiental [NUGEO], 2016). O Alto Itapecuru vai da nascente até o município de Colinas. Geomorfologicamente há uma predominância de chapadões, chapadas e cuestas, apresentado um relevo forte ondulado. O Médio Itapecuru corresponde do município de colinas até o município de Caxias. Esta área predomina o relevo de chapadas baixas e uma superfície suave ondulado a forte ondulado. O Baixo Itapecuru compreende do município de Caxias até a foz, na Baía de São José. Essa área possui uma geomorfologia caracterizada por um relevo de superfície suave ondulado e possui o trecho de maior navegabilidade (Alcântara, 2004).

Os principais tipos de vegetação encontrados na bacia compõem o Bioma cerrado, que são subclassificadas como savana com variações definidas como aberta, arbórea e de parque. Pode apresentar também áreas alag adas com características de mangue, florestas, vegetação secundária, além de atividades agropecuárias e agrícolas que interferem diretamente na distribuição da vegetação ao longo da bacia (Silva et al., 2017). Seus recursos hídricos têm múltiplos usos, dos quais se pode destacar: o abastecimento de São Luís/MA e das cidades inseridas na bacia, transporte, recreação, dessedentação de animais, irrigação, agricultura de vazante, dentre outros (Santos \& Leal, 2010).

A bacia hidrográfica do rio Itapecuru possui ecossistemas de vasta diversidade biológica e de recursos hídricos, que estão sendo usados para a ampliação do agronegócio e da expansão agrícola. As enchentes que ocorrem, são comumente ocasionadas por problemas geoambientais provenientes de alterações naturais e especialmente de ações antrópicas que envolvem a remoção da vegetação natural que protegem as margens do rio (CODEVASF, 2019; Jesus Silva \& Conceição, 2011, Masullo et al., 2019).

A degradação dos recursos ambientais na bacia do rio Itapecuru se caracteriza essencialmente pelo uso desordenado para o abastecimento humano, industrial e produtividade agropecuária. Com o uso não sustentável dos recursos naturais, notase o avanço do assoreamento em seu leito e de seus tributários, a degradação das nascentes, os inúmeros danos nas matas ciliares e da vegetação de outras Áreas de Preservação Permanentes (APPs). Correlacionado a isto, se verifica também a poluição por efluentes lançados in natura nos recursos hídricos da bacia, o desmatamento e as queimadas (Barroso \& Pádua Sousa, 2007; CODEVASF, 2019; Feitosa \& Almeida, 2002; Silva Pereira et al., 2020).

Nos últimos anos o rio Itapecuru tem passado por diversas modificações em seus processos sistêmicos, sendo alguns deles influenciados principalmente por ações irregulares de origem humana, destacando-se o lançamento de efluentes sem tratamento ao longo de sua extensão, originários da ocupação e urbanização desorganizada, devido à construção de imóveis irregulares e inadequadas em suas margens (CODEVASF, 2019; Jesus Silva \& Conceição, 2011; Silva Pereira et al., 2020).

Pereira, Brito Nunes \& Silva Araújo (2021) ao analisar a ocupação e cobertura da terra no município de Caxias-MA concluiu que, há uma vasta diversidade de impactos socioambientais ocorrendo nessa região, sendo os mais predominantes: a remoção da vegetação natural especialmente para a construção de imóveis, o assoreamento nos rios, habitações em localidades consideradas impróprias (limítrofe a encostas), despejos de resíduos domésticos em locais em que se encontra uma natureza preservada e a contaminação por efluentes nos corpos hídricos, o que ocasiona prejuízos para a fauna e para flora.

É fundamental que o rio Itapecuru, apresente condições físicas e químicas adequadas para poder ser utilizado pelos seres vivos. Na água devem estar presentes substâncias essenciais à vida e isentas de outras que possam produzir efeitos adversos que causem danos à saúde dos organismos e comprometimentos aos diversos segmentos que se beneficiam deste recurso natural. Nesse cenário, a disponibilidade de água não significa unicamente quantidade adequada, mas também qualidade satisfatória para atender a biota do Leste Maranhense. 
O presente trabalho é um estudo pioneiro no que se refere à análise dos quatro elementos básicos $(\mathrm{pH}$, oxigênio dissolvido, condutividade e temperatura) no curso do rio Itapecuru que percorre a cidade de Caxias-MA e teve como objetivo analisar a qualidade de água do rio Itapecuru em termos de parâmetros físico-químicos, verificando se a água do rio está em conformidade com a legislação vigente para águas doces, a fim de observar se está oferecendo algum risco à saúde ou ao meio ambiente.

\section{Metodologia}

\section{1 Área de estudo}

O presente estudo é de natureza experimental, com abordagem quanti-qualitativa e foi realizado no município de Caxias, que pertence ao médio curso da bacia hidrográfica do rio Itapecuru. A cidade de Caxias está inserida na Mesorregião Leste maranhense, dentro da Microrregião de Caxias, compreendendo uma área de 5.201,927 Km², uma população de aproximadamente 166.159 habitantes e uma densidade demográfica de 30,12 habitantes $/ \mathrm{Km}^{2}$, segundo dados do Instituto Brasileiro de Geografia e Estatística - IBGE (2021). Limita-se ao Norte com o município de Coelho Neto; ao Sul, com Parnarama; a Leste, com Timon, Matões e águas do rio Parnaíba e; a Oeste, com Aldeias Altas, São João do Sóter e Codó (Correia Filho et al., 2011).

Em termos geomorfológicos, o município de Caxias se enquadra como um relevo plano e levemente ondulado, enquadrado na unidade geomorfológica designada Superfície Maranhense. Na vegetação identifica-se a predominância de diferentes zonas como a zona dos cocais, o cerrado e a zona pré-amazônica, sendo localizadas mata de galerias e babaçuais (Jesus Silva \& Conceição, 2011). O clima de acordo com a classificação de Köppen é tropical semiúmido, com duas fases bem definidas: chuvosa (de janeiro a junho) e seca (de julho a dezembro). A precipitação pluviométrica mais acentuada na região abrange o período de janeiro a abril, com intensa ação e influência da ZCIT (Zona de Convergência Intertropical) na qual a média pluviométrica é excedida (Rosário, Lima \& Brito Nunes, 2020).

\subsection{Localização dos pontos de amostragem}

Com base em imagens de satélite da ferramenta Google Earth® foram selecionados 10 pontos de amostragem no percurso do rio Itapecuru que perpassa o município de Caxias-MA no sentido jusante $\rightarrow$ montante, eles foram selecionados objetivando indicar possíveis alterações na qualidade da água, optando por áreas demarcadas dentro do perímetro urbano onde ocorrem despejos de efluentes ou onde há atividades humanas poluidoras, áreas urbanizadas de balneabilidade, locais com presença e ausência de vegetação nas margens dos canais fluviais e áreas rurais sem lançamentos de efluentes, para estabelecer uma comparação. As coordenadas dos locais de coletas foram obtidas por meio de aparelho GPS Garmin Etrex e estão abaixo descritas na Tabela 1. 
Tabela 1 - Coordenadas dos pontos amostrais selecionados para este estudo.

\begin{tabular}{c|cc}
\hline \multirow{2}{*}{ Pontos de coleta } & \multicolumn{2}{|c}{ Coordenadas Geográficas } \\
\cline { 2 - 3 } & Latitude & Longitude \\
\hline P1 & $05^{\circ} 02.147^{\prime}$ & $043^{\circ} 24.092^{\prime}$ \\
P2 & $04^{\circ} 54.919^{\prime}$ & $043^{\circ} 21.464^{\prime}$ \\
P3 & $04^{\circ} 53.431^{\prime}$ & $043^{\circ} 21.643^{\prime}$ \\
P4 & $04^{\circ} 53.375^{\prime}$ & $043^{\circ} 21.710^{\prime}$ \\
P5 & $04^{\circ} 52.089^{\prime}$ & $043^{\circ} 21.825^{\prime}$ \\
P6 & $04^{\circ} 51.589^{\prime}$ & $043^{\circ} 21.542^{\prime}$ \\
P7 & $04^{\circ} 51.892^{\prime}$ & $043^{\circ} 22.067^{\prime}$ \\
P8 & $04^{\circ} 51.449^{\prime}$ & $043^{\circ} 22.082^{\prime}$ \\
P9 & $04^{\circ} 49.970^{\prime}$ & $043^{\circ} 22.092^{\prime}$ \\
P10 & $04^{\circ} 49.771^{\prime}$ & $043^{\circ} 22.101^{\prime}$ \\
\hline
\end{tabular}

Fonte: Aparelho Garmin Etrex H Handheld GPS Navigator.

As coordenadas foram exportadas para o software livre QGIS (versão 2.6), para a confecção do mapa hidrológico, com o shape da bacia hidrográfica do rio Itapecuru, que se encontra abaixo, na Figura 1.

Figura 1 - Mapa Hidrológico dos pontos de coleta no rio Itapecuru no município de Caxias-MA.
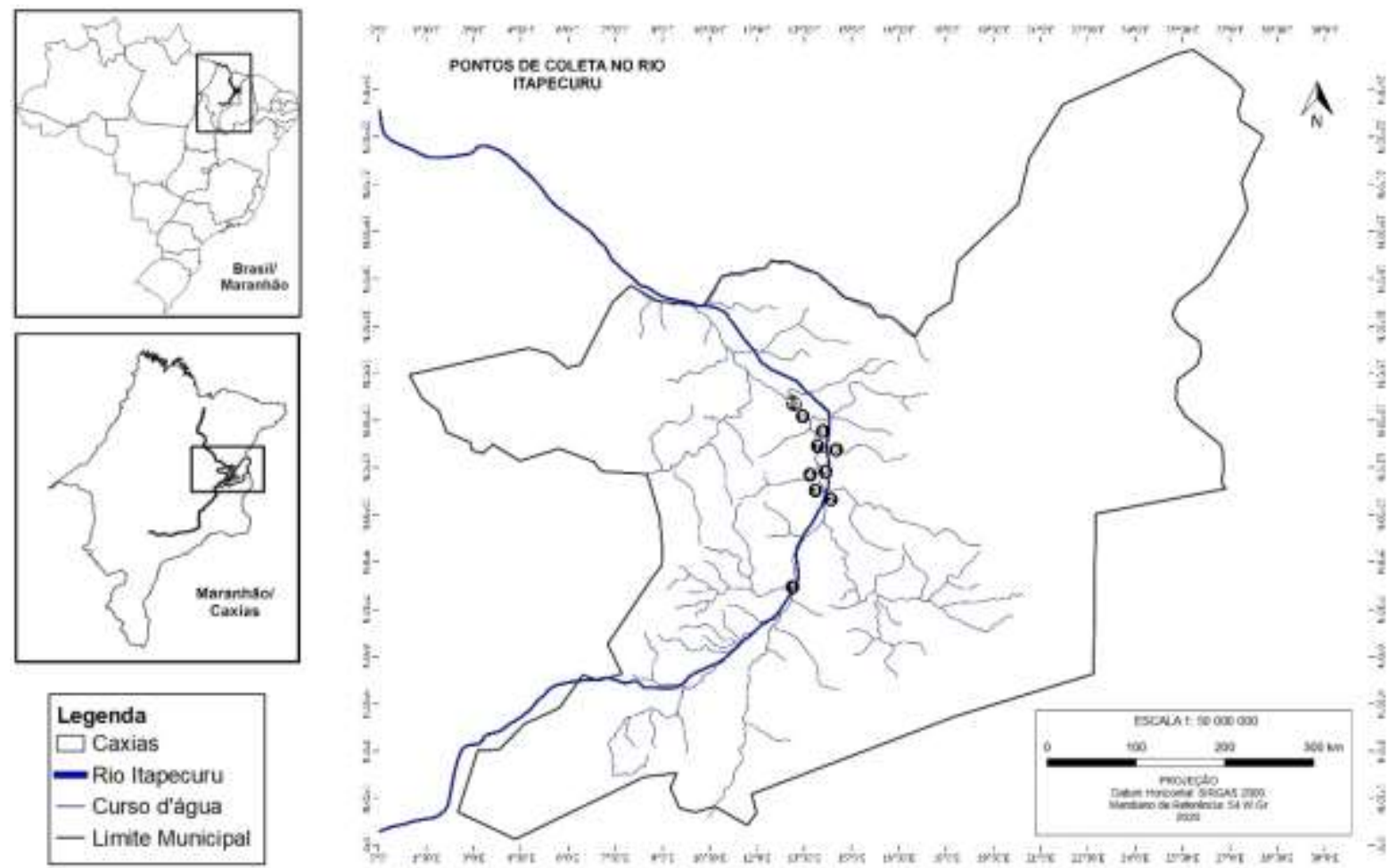

Elaboração: software QGIS. Fonte: Autores (2021).

\subsection{Procedimentos utilizados para mensuração dos parâmetros}

As análises dos parâmetros físicos e químicos que permitiram avaliar a qualidade da água foram realizadas entre 22 de julho a 08 de setembro de 2021, no período seco para evitar efeitos de diluição que geralmente ocorrem no período chuvoso. As análises foram efetuadas semanalmente, cada teste foi realizado em triplicata para a obtenção de uma média mais precisa, assim como no estudo realizado por Câmara (2011), sendo nomeadas como amostragem um (A1), amostragem dois (A2) e 
amostragem três (A3), totalizando 30 elementos amostrais. Cabe ressaltar que todos os procedimentos de campo foram realizados no período da manhã, levando em consideração o mesmo horário para evitar interferências nos resultados.

No momento de cada análise, foram realizados registros fotográficos, bem como, das coordenadas de cada seção amostral, que foram obtidas por meio de aparelho GPS Garmin Etrex. Para execução dos testes, as aferições dos parâmetros foram realizadas in situ, evitando falso resultado por causa da locomoção das amostras até o laboratório. Os parâmetros físicoquímicos analisados foram: temperatura da água, condutividade elétrica, potencial hidrogeniônico (pH) e oxigênio dissolvido.

Os equipamentos portáteis eram calibrados no laboratório, de acordo com o protocolo de cada aparelho, a medição dos parâmetros em campo era realizada inserindo-se o eletrodo de cada uma das sondas diretamente na água do curso do rio, e aguardava-se a numeração estabilizar para realizar a leitura, o eletrodo era sempre lavado com água destilada antes da aferição. Nas coletas foram utilizados os seguintes equipamentos: medidor de $\mathrm{pH}$ digital, marca: Akso, modelo: AK90, o qual mediu o pH e a temperatura da água; condutivímetro digital portátil, marca: Instrutherm, modelo: CD-850, que aferiu a condutividade da água e o medidor de oxigênio dissolvido na água portátil, marca: BES, modelo: JPB70, o qual mensurou a quantidade de oxigênio dissolvido na água.

Os pontos foram caracterizados como pontos com ou sem contaminantes, sendo considerada uma parcela de 30 metros, com 15 metros para a direita e 15 metros para a esquerda do ponto demarcado no GPS, os pontos P2, P5, P6, P7 e P8 como pontos que não recebem contaminantes diretamente, e os pontos P1, P3, P4, P9 e P10 como pontos que recebem contaminantes diretamente em seu leito, na Figura 2 tem-se as imagens dos dez pontos de coleta.

Figura 2 - Fotos dos locais de amostragem.

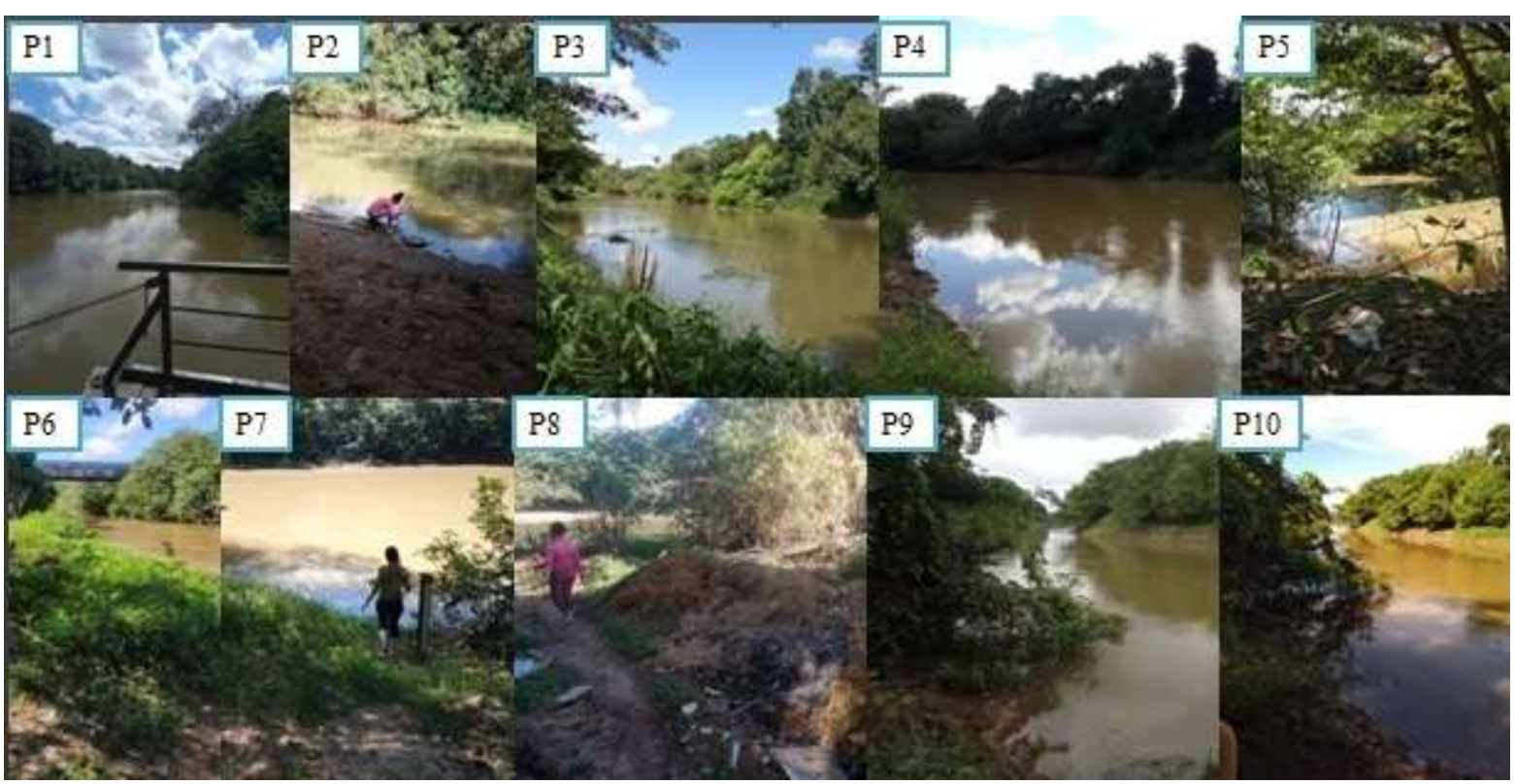

Fonte: Autores (2021).

Os dados das coletas foram organizados em banco de dados em formato XLSX, utilizando o software Microsoft Excel 2010, para análise estatística dos dados e elaboração dos gráficos foram utilizados a média aritmética e o desvio padrão. 


\section{Resultados e Discussão}

\subsection{Parâmetros físicos}

Os parâmetros físicos analisados no trabalho foram: temperatura e condutividade elétrica da água. São considerados os mais comuns de serem mensurados, sendo geralmente partículas sólidas presentes na água, que de acordo com seu tamanho podem estar em suspensão, dissolvidos na água ou coloidais (Campos, 2017).

\subsubsection{Temperatura da água}

Não houve uma variação expressiva da temperatura da água ao longo das coletas, sendo a média geral dos pontos de 27,8 $\mathrm{C}$ (Gráfico 1). Baseado nos valores das informações do Programa Nacional de Avaliação da Qualidade das Águas PNQA, a temperatura média das águas do rio Itapecuru observada no presente estudo encontra-se acima do limite permitido para Classe 2 em relação a balneabilidade (Instituto Maranhense de Estudos Socioeconômicos Cartográficos [IMESC], 2019). No que se refere à Resolução do Conselho Nacional do Meio Ambiente- CONAMA 357/2005 a temperatura deve ser igual ou inferior a $40^{\circ} \mathrm{C}$, mas isso é considerado para lançamento de efluentes na água (Brasil, 2005).

Gráfico 1- Temperatura da água, contendo os valores dos 10 pontos e suas respectivas amostragens.

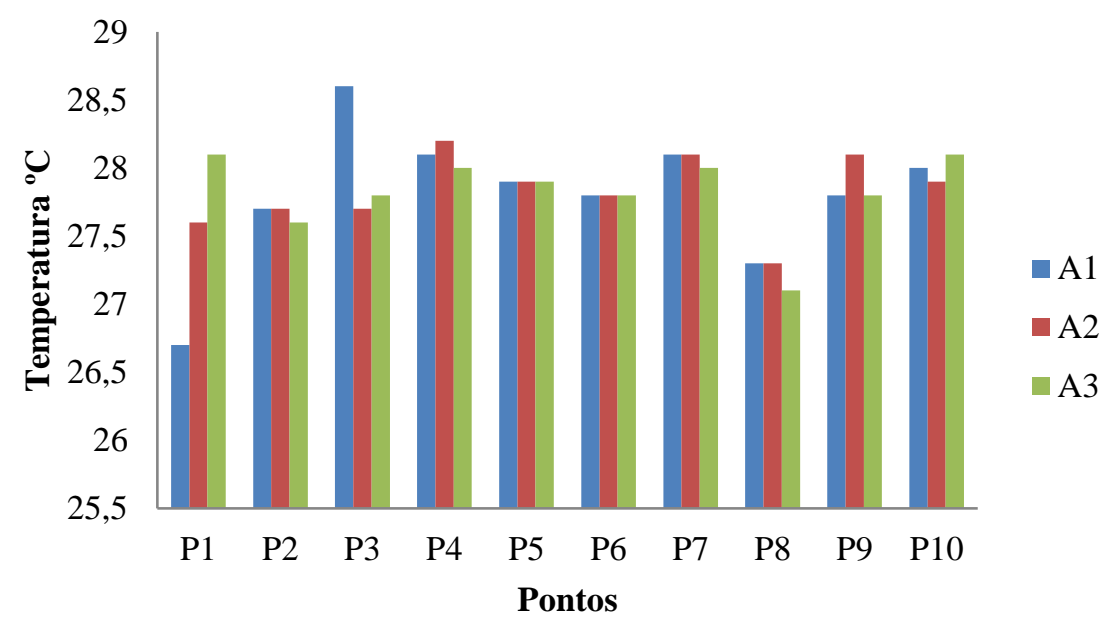

Fonte: Autores (2021).

O ponto P1 localizado na zona rural da cidade apresentou o menor valor de temperatura na primeira amostragem, com $26,7{ }^{\circ} \mathrm{C}$ e o ponto 3 que se encontra dentro do perímetro urbano, apresentou o maior valor de temperatura na primeira amostragem, com $28,6^{\circ} \mathrm{C}$, o estudo de Nogueira, Costa e Pereira (2015), corrobora com esses dados, pois eles afirmam que a temperatura da água da zona rural é mais amena que a da zona urbana, além da presença maior de vegetação.

Determinados fatores que contribuem na atenuação da temperatura, como a diminuição da incidência de raios solares no corpo hídrico por apresentar uma densa vegetação caracteriza a grande importância da preservação das matas ciliares para se obter melhores condições de temperatura no corpo d'água (Nogueira, Costa \& Pereira, 2015). O ponto 5 e o ponto 6 não apresentaram variação nas temperaturas, apresentando assim uma média igual das aferições, sendo portanto o desvio padrão igual à zero (Gráfico 2). 
Gráfico 2 - Médias e desvio padrão da temperatura da água, nos pontos de 1 a 10.

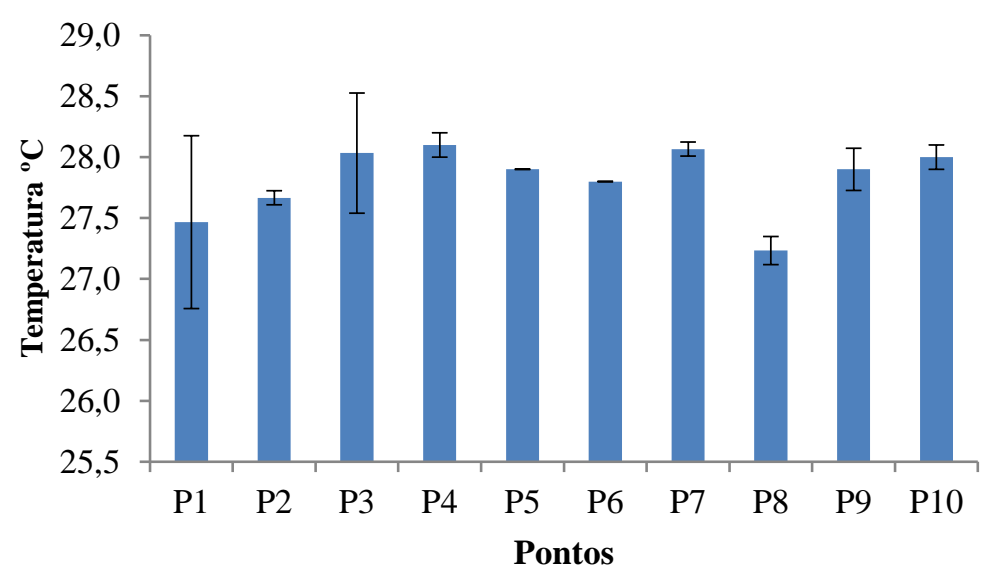

Colunas na cor azul: médias das temperaturas de cada ponto. Barras na cor preta: valores de desvio padrão. Fonte: Autores (2021).

O ponto 1 apresentou uma oscilação de temperatura entre as amostragens, o que ocasionou o maior desvio padrão de todos os pontos, sendo de 0,71 . A elevação da temperatura da água pode ser de origem natural, mediante a transferência de calor por: condução, radiação e convecção (solo e atmosfera) ou de origem antropogênica, por intermédio das águas de torres de resfriamento e resíduos industriais (Von Sperling, 2005). Esse fato pode ser observado devido a esse local estar situado em uma área de lazer e turismo utilizado para fins de balneabilidade, especialmente aos domingos.

As maiores médias de temperatura apresentadas foram nos pontos 4 e 7 ambas com $28,1^{\circ} \mathrm{C}$ e a menor média foi 27,5 ${ }^{\circ} \mathrm{C}$, sendo aferida no ponto 1 , que se encontra na zona rural. Nas duas campanhas realizadas por Almeida (2019) no rio Itapecuru na Cidade de Codó, as médias da temperatura da água variaram de 28,7 a $29,7^{\circ} \mathrm{C}$. Libâneo (2010) afirma que a temperatura é proporcional à aceleração das reações químicas que praticamente duplicam para um aumento de $10^{\circ} \mathrm{C}$ na temperatura dos corpos hídricos, à dissolubilidade de substâncias, à quantidade do oxigênio dissolvido disponível, ao metabolismo das espécies que existem no ecossistema aquático, à constituição de resquícios de desinfecção, ao aparecimento microbiológico acentuado e ao percentual de corrosão nas canalizações completivas dos programas de abastecimento.

\subsubsection{Condutividade elétrica}

A maior condutividade apresentada foi no P2, onde as três aferições foram as maiores observadas de todos os pontos sendo elas: $62,1 \mu \mathrm{S} / \mathrm{cm}, 60,2 \mu \mathrm{S} / \mathrm{cm}$ e 59,4 $\mu \mathrm{S} / \mathrm{cm}$, essa localidade recebe esgoto não tratado diretamente em seu curso, o que pode ter influenciado nesse resultado, além de estar localizado próximo ao balneário Veneza, que é um dos balneários mais visitados da cidade de Caxias (Gráfico 3).

Esse parâmetro aponta a capacidade da água conduzir corrente elétrica de acordo com o aparecimento de substâncias que se dissociam em cátions e ânions, geralmente íons de manganês e ferro, além de $\mathrm{Na}^{+}, \mathrm{K}^{+}, \mathrm{Ca}^{+2}, \mathrm{Cl}^{-}, \mathrm{Mg}^{+2}$, tornando-se proporcional a concentração iônica, de forma direta. Soluções onde se apresentam a maior parcela dos compostos inorgânicos manifestam condutividade alta, em compensação, compostos orgânicos que não se dissociam em soluções aquosas, no momento em que se apresentam atenuam a passagem da corrente elétrica (Libâneo, 2010).

São diversos os fatores que podem alterar os recursos hídricos, mas um dos mais relevantes são as ações humanas, no que se concerne ao uso e ocupação do solo. As ocupações existentes em uma bacia hidrográfica ou em uma UPH (Unidades de Planejamento Hídrico) geralmente não pensam nas qualidades e as vulnerabilidades dela, a vista disso, provocam prejuízos irreparáveis. As ações antrópicas irregulares estimulam os processos do meio físico como: erosão e assoreamento, o que se tem 
como consequência a destruição de cursos d'águas, como pode ser observado nesse ponto próximo a Veneza (Queiroz Ribeiro, et al.,2019).

Gráfico 3 - Condutividade da água, contendo os valores dos 10 pontos e suas respectivas amostragens.

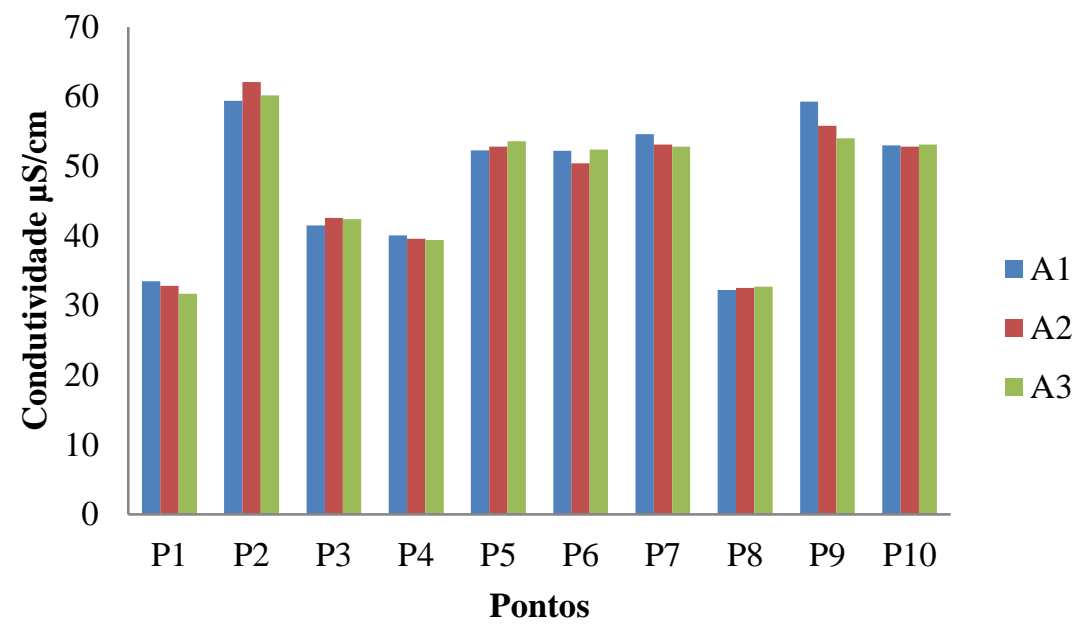

Fonte: Autores (2021).

Foram observadas grandes quantidades de macrófitas nas proximidades do ponto 2, assim como na pesquisa de Souza Junior e Oliveira (2016), esses autores indicam que a elevação da condutividade pode estar associada à decomposição de plantas cobertas pelas águas ou por apresentar resíduos orgânicos, circunstâncias que podem originar uma maior dispensa de íons no leito do rio.

Segundo Libâneo (2010) a condutividade se demonstra importante em localidades vulneráveis a altas taxas de evaporação e menor intensidade pluviométrica, ocasionalmente exibindo balanço hídrico negativo, como em determinados estados da Região Nordeste. A maior média de condutividade apresentada foi no ponto 2 , sendo de $60,57 \mu \mathrm{S} / \mathrm{cm}$, com desvio padrão de 1,39 e a menor média foi no ponto 8 , de $32,47 \mu \mathrm{S} / \mathrm{cm}$, com desvio padrão de 0,25 (Gráfico 4).

Gráfico 4 - Médias e desvio padrão da condutividade da água, nos pontos de 1 a 10.

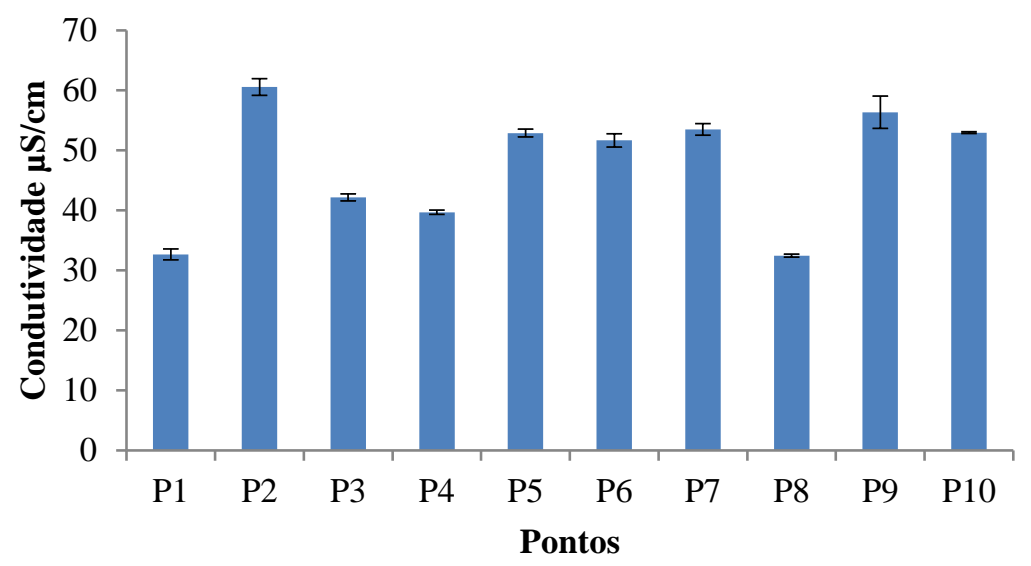

Colunas na cor azul: médias de condutividade de cada ponto. Barras na cor preta: valores de desvio padrão. Fonte: Autores (2021).

As águas naturais indicam geralmente condutividade elétrica inferior a $100 \mu \mathrm{S} / \mathrm{cm}$, sendo capaz de alcançar 1000 $\mu \mathrm{S} / \mathrm{cm}$ em corpos hídricos que recebem altíssimas cargas de efluentes industriais ou domésticos (Libâneo, 2010). Desse modo 
a água analisada do rio Itapecuru em Caxias em relação ao parâmetro da condutividade encontra-se dentro do padrão. Nas duas campanhas realizadas por Almeida (2019) as aferições médias de condutividade foram de 111,3 $\mu \mathrm{S} / \mathrm{cm}$ com desvio padrão de 5,77 e $98,7 \mu \mathrm{S} / \mathrm{cm}$ com desvio padrão de 16,74, já no estudo de Martins (2019) foram entre 53,86 $\mu \mathrm{S} / \mathrm{cm}$ e $81,78 \mu \mathrm{S} / \mathrm{cm}$.

\subsection{Parâmetros químicos}

Os parâmetros químicos analisados na pesquisa foram: potencial hidrogeniônico e oxigênio dissolvido. Esses compostos químicos fornecem análises mais específicas sobre a qualidade da água, do ponto de vista econômico e sanitário. São substâncias químicas orgânicas (compostos do carbono, que compõem majoritariamente seres animais e vegetais) ou inorgânicas (como os minerais) encontradas na água (Silva, 2017).

\subsubsection{Potencial hidrogeniônico}

Nos resultados das três coletas em cada ponto amostral, o maior $\mathrm{pH}$ apresentando foi no ponto 1 (primeira amostragem) sendo de 7,9 e o menor registro de $\mathrm{pH}$ foi no ponto 4 (primeira amostragem) com pH de 6,5 (Gráfico 5). O pH é equivalente a concentração dos íons $\mathrm{H}^{+}$nas águas e caracteriza a amplitude de classes ácidas ou alcalinas do meio aquático (Libâneo, 2010). Esse indicador é utilizado com maior frequência na caracterização de águas de abastecimento brutas ou tratadas e de águas residuárias, no controle dos procedimentos de estações de tratamento de água (coagulação, desinfecção, e grau de incrustabilidade/ corrosividade, remoção da dureza), monitoramento da operação de estações de tratamento de esgotos e na definição de corpos d'água (Von Sperling, 2005).

Gráfico 5 - Potencial hidrogeniônico da água, contendo os valores dos 10 pontos e suas respectivas amostragens.

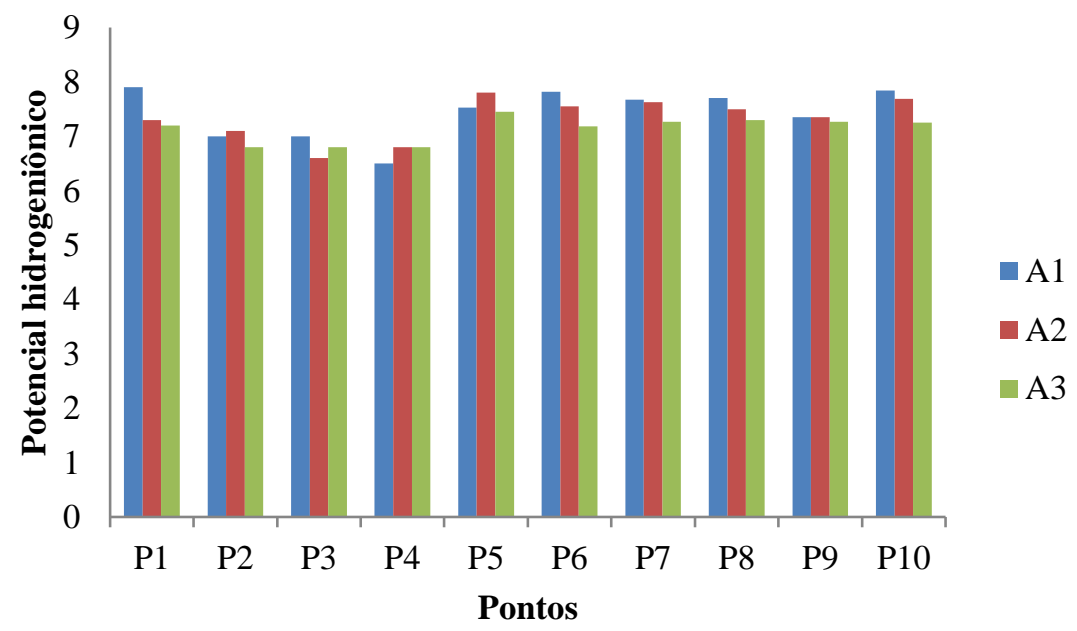

Fonte: Autores (2021).

Na pesquisa de Martins (2019) as médias do pH no rio Itapecuru no município de Itapecuru-Mirim variaram entre 6,2 e 7,38. O potencial hidrogeniônico tem influência no grau de solubilidade de inúmeras substancias, na intensidade da cor, na organização das formas livre e ionizada de vários compostos químicos, podendo também determinar o potencial de toxicidade de diversos elementos (Libâneo, 2010). A faixa de pH varia de 0 a 14, nos resultados, quando menor que 7 apresenta condições ácidas, quando igual a 7 está no nível de neutralidade e quando maior que 7 demonstra condições básicas (Von Sperling, 2005).

Identificou-se a maior média nos pontos 5 e 10, ambos com pH de 7,6 o que define essas amostras como básicas, já a menor média aferida foi a do ponto 4 com 6,7 e desvio padrão de 0,18 , o que indica um nível de acidez na amostra. O ponto 2 
apresentou um pH igual a 7, sendo portando neutro (Gráfico 6). A Resolução do CONAMA 357/2005 recomenda que os valores de $\mathrm{pH}$ para classe 2, estejam entre a faixa de 6,0 a 9,0, portanto os resultados obtidos no trabalho encontram-se dentro dos valores preconizados pela legislação vigente (Brasil, 2005).

Gráfico 6 - Médias e desvio padrão do potencial hidrogeniônico da água, nos pontos de 1 a 10.

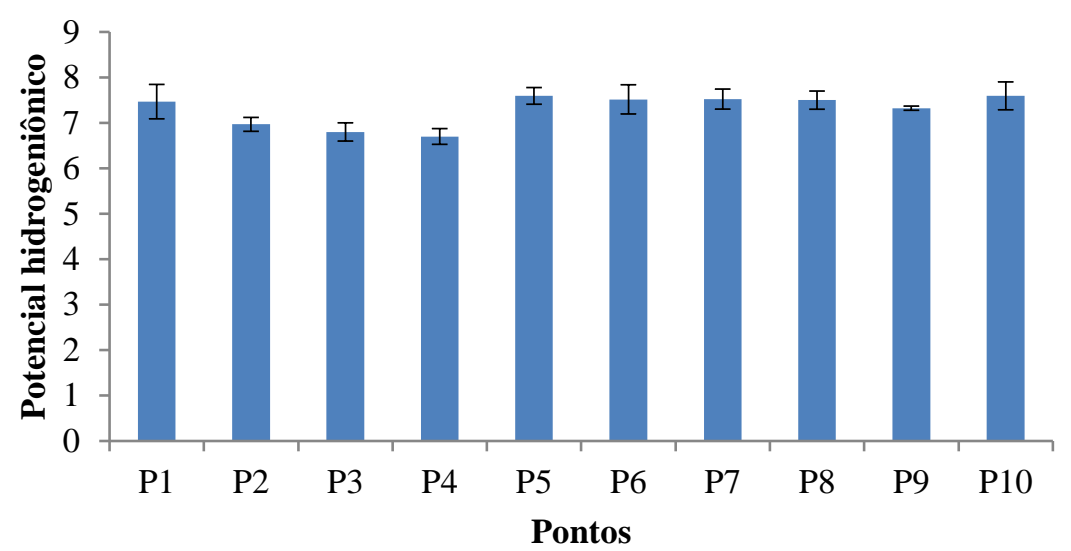

Colunas na cor azul: médias de pH de cada ponto. Barras na cor preta: valores de desvio padrão. Fonte: Autores (2021).

Na primeira e na segunda campanha realizada por Almeida (2019) as média do pH foram de 6,0 com desvio padrão igual a zero, o que classifica as águas do rio Itapecuru na região de Codó como ácidas. Dados obtidos do PNQA para o rio Itapecuru verificaram que o menor $\mathrm{pH}$ foi de 5,13 e o maior foi o de 7,42 (IMESC, 2019). Castro (2016) em seu trabalho sobre tributários do rio Itapecuru no município de Caxias-MA, aferiu medições de pH, com a menor média de 4,7 e maior média de 7,15. Gaspar \& Conceição (2017) mensuraram um pH no riacho Ouro com valor mínimo de 6,2 e valor máximo de 7,2, resultados mais baixos do que os apresentados no presente trabalho, o que pode ter sido ocasionado pelo fato dos trabalhos terem sido realizados em riachos e não diretamente no rio Itapecuru.

\subsubsection{Oxigênio dissolvido}

O maior valor aferido desse indicador foi de $11 \mathrm{mg} / \mathrm{L}$ no ponto 1 e o menor valor foi de 4,6 mg/L no ponto 8 (Gráfico 7). Segundo Von Sperling (2005) o oxigênio dissolvido (OD) é o parâmetro fundamental de descrição dos impactos da poluição nos corpos hídricos por despejos orgânicos. A Resolução do CONAMA 357/2005 preconiza que o oxigênio dissolvido, em qualquer amostra, não deve ser abaixo a $5 \mathrm{mg} / \mathrm{L} \mathrm{O}_{2}$ (Brasil, 2005). O ponto 8 localiza-se próximo ao mercado central de Caxias onde nota-se a presença de queimadas, despejos de esgotos residenciais e a existência de lixos de diversos tipos próximos a margem do rio.

Na pesquisa de Silva Pereira et al., (2020) identificou os principais impactos ambientais do rio Itapecuru, dentre os citados destacou-se: o descarte de resíduos sólidos de origem doméstica e lançamento de efluentes in natura diretamente no curso do rio, a prática de arremessar cadáveres de animais no leito do rio e a supressão da mata ciliar, o que ocasiona diversas problemáticas no que se concerne à poluição, a falta de equilíbrio no ecossistema e o odor desagradável no local, o que foi similarmente constatado ao realizar as coletas nesse ponto. 
Gráfico 7 - Oxigênio dissolvido da água, contendo os valores dos 10 pontos e suas respectivas amostragens.

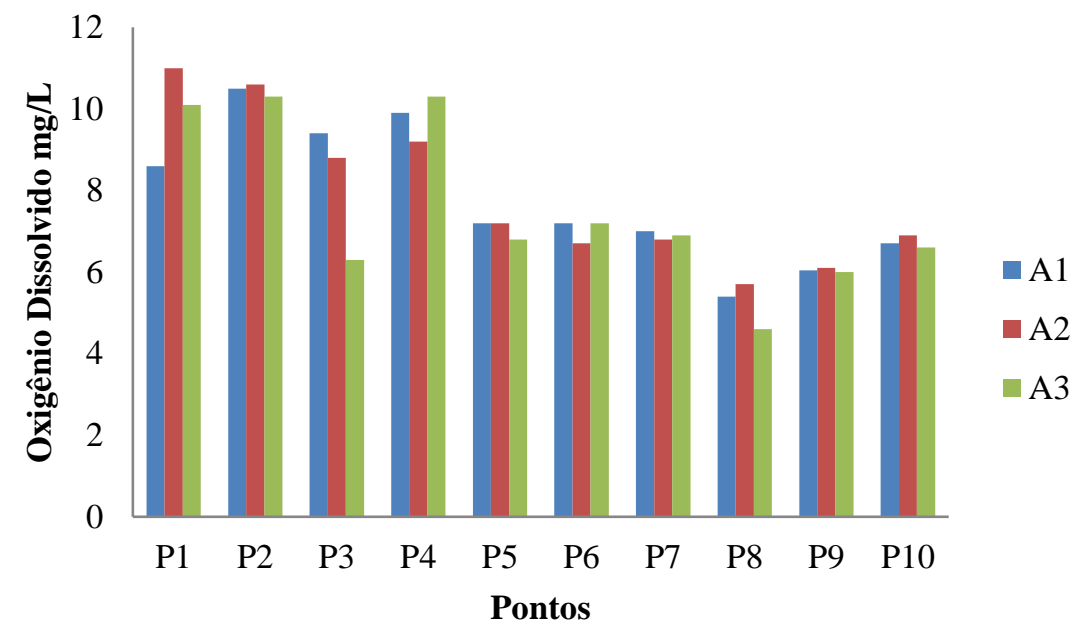

Fonte: Autores (2021).

Nos pontos com presença de ações antropogênicas, notou-se a diminuição da concentração de OD, que é diretamente proporcionada pela pressão atmosférica, ou de maneira inversa a altitude, e de modo indireto proporcional a temperatura. A atenuação do OD pode acontecer por causas naturais, principalmente pela respiração de organismos aeróbicos ou pela decomposição da matéria orgânica pelos organismos existentes no ecossistema aquático. Outra maneira de redução do OD nos corpos hídricos relaciona-se aos poluentes na atmosfera e a oxidação de íons (Libâneo, 2010).

A maior média foi de 10,47 mg/L, sendo encontrada no ponto 2, com desvio padrão de 1,64 e a menor média foi no ponto 8 com 5,23 mg/L com desvio padrão de 0,57 (Gráfico 8). De acordo com o IMESC (2019) a média das leituras realizadas entre $06 / 2005$ até $07 / 2017$ foi de $6,488 \mathrm{mg} / \mathrm{L}$ e a média geral do presente trabalho foi de 7,735, o que caracteriza o oxigênio dissolvido encontrado maior que o esperado.

Gráfico 8 - Médias e desvio padrão do oxigênio dissolvido da água, nos pontos de 1 a 10.

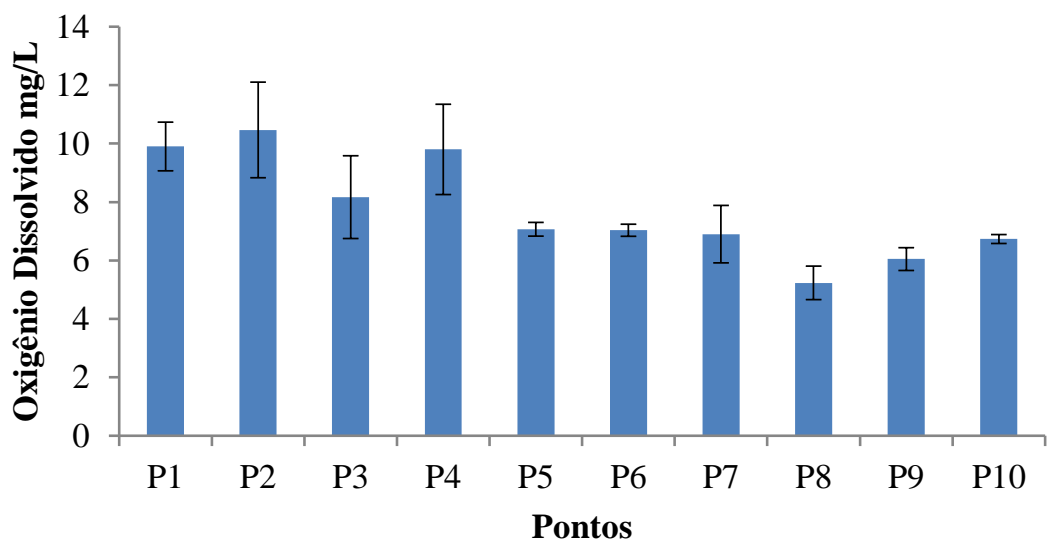

Colunas na cor azul: médias de oxigênio dissolvido de cada ponto. Barras na cor preta: valores de desvio padrão. Fonte: Autores (2021).

Nos dados do trabalho de Ferro et al., (2018) apontam que 60\% dos moradores ribeirinhos lançam seus esgotos residenciais diretamente no rio Itapecuru e somente $30 \%$ da população amostral do estudo utilizam a rede de esgotos. O ponto 8 tem uma elevada influência da antropização e se encontra no limite do que é recomendado para a sobrevivência da biota aquática (Brasil, 2005). 
As alterações nos teores de OD estão relacionadas às ações biológicas, químicas e físicas, que acontecem nos cursos hídricos. Para a preservação da biota aquática aeróbia são indispensáveis teores de oxigênio dissolvido de 2 a $5 \mathrm{mg} / \mathrm{L}$, conforme o grau de necessidade de cada organismo. A quantidade de oxigênio à disposição mínima fundamental para a manutenção da vida das espécies de água doce é de $4 \mathrm{mg} / \mathrm{L}$, e para a maior parte dos peixes é de $5 \mathrm{mg} / \mathrm{L}$ (Libâneo, 2010).

No estudo de Martins (2019) em relação à classe 2, 58,3\% das amostragens estavam em desconformidade, já em relação à classe 3 esse percentual foi de 50\%. Em adição as ações antropogênicas no despejo de efluentes, as concentrações de OD podem se alterar de maneira natural. Corpos d'água de velocidade maior beneficiam a contribuição do oxigênio da atmosfera, este acontecimento nomeado de supersaturação de $O D$ acontece exclusivamente pela atuação fotossintética (Libâneo, 2010; Von Sperling, 2005).

\section{Conclusão}

Conforme as análises realizadas no trabalho, a qualidade da água do rio Itapecuru no Leste Maranhense, na cidade de Caxias-MA, em relação aos parâmetros físico-químicos: a temperatura dá água está acima do limite permitido para Classe 2 de acordo com o do PNQA para o rio Itapecuru; condutividade elétrica encontra-se dentro do padrão para águas naturais segundo Libâneo; potencial hidrogeniônico e oxigênio dissolvido estão inclusos no que a Resolução do CONAMA 357 preconiza.

Esse estudo oferece informações para a população que utiliza esse recurso hídrico, mostrando como as ações antrópicas interferem na qualidade físico-química das águas do rio Itapecuru, evidenciando uma necessidade de monitoramento da qualidade da água. Por ser uma pesquisa pioneira no que se refere à análise de parâmetros físico-químicos verificados em todo o curso do rio Itapecuru que perpassa o município de Caxias-MA, tendo como base o PNQA da ANA que realiza a análise dos quatro elementos básicos: pH, oxigênio dissolvido, condutividade e temperatura e a resolução CONAMA 357, ele serve de base para que estudos posteriores em relação ao tema possam se fundamentar.

\section{Agradecimentos}

À Universidade Estadual do Maranhão - CESC-UEMA.

Ao Instituto Federal de Educação, Ciência e Tecnologia do Maranhão- Campus Caxias.

Ao Laboratório de Entomologia Aquática - Leaq (CESC-UEMA).

Aos discentes que colaboram nas coletas da pesquisa.

\section{Referências}

Agência Nacional de Água - ANA. (2019). Conjuntura de recursos hídricos no Brasil; Brasília.

Al-Aboodi, A. H., Abbas, S. A., \& Ibrahim, H. T. (2018). Effect of Hartha and Najibia power plants on water quality indices of Shatt Al-Arab River, south of Iraq. Applied Water Science, 8(2), 1-10.

Alcântara, E. H. (2004). Caracterização da Bacia Hidrográfica do rio Itapecuru, Maranhão-Brasil. Caminhos de Geografia, 5(11).

Almeida, U. S. D. (2019). Avaliação da qualidade da água do rio Itapecuru: Análise Físico-Química e Impactos Antrópicos.

Alves, L. M. C. (2010). Qualidade da água de múltiplos usos na microrregião de Itapecuru-Mirim-MA.

Bacci, D. D. L. C., \& Pataca, E. M. (2008). Educação para a água. Estudos avançados, 22, 211-226.

Barroso, H. G., \& de Pádua Sousa, A. (2007). Áreas potenciais para a aquicultura sustentável na bacia do rio Itapecuru: bases para o planejamento com uso do Sistema de Informação Geográfica. Revista Brasileira de Engenharia de Pesca, 2(1), 80-102.

Bicudo, C. E. M., Tundisi, J.G. \& Scheuenstuhl, M. C. B. (2010). Águas do Brasil: análises estratégicas. Instituto de Botânica. São Paulo.

Brasil. (1997). Lei 9.433, de 08 de janeiro de 1997. Institui a política nacional de recursos hídricos, cria o sistema nacional de gerenciamento de recursos hídricos, regulamenta o inciso XIX do art. 21 da Constituição federal, e altera o art. $1^{\circ}$ da Lei 8.001, de 13 de março de 1990 , que modificou a Lei 7.990 , de 28 de dezembro de 1989. Diário Oficial da União. Seção 1, p. 470. 
Brasil. (2005). Resolução no 357, de 17 de março de 2005. Dispõe sobre a classificação dos corpos de água e diretrizes ambientais para o seu enquadramento, bem como estabelece as condições e padrões de lançamento de efluentes, e dá outras providências. Diário Oficial da União, 1, 58-63.

Brasil. (2018). Qualidade da Água para Consumo Humano cartilha para promoção e proteção da saúde.

Brasil. (2006). Ministério do Meio Ambiente. Secretaria de Recursos Hídricos. Caderno da Região Hidrográfica Atlântico Nordeste Ocidental. Brasília.

Câmara, F. D. M. M. (2011). Avaliação da qualidade da água do rio Poti na cidade de Teresina, Piauí.

Campos, L. M. V. (2017). Avaliação da qualidade da água destinada ao consumo humano do município de Iguatama-MG.

Carvalho, J. W. L. T., Marangon, F. H. S., \& Santos, I. (2020). Recuperação de rios urbanos: da interdependência e sincronicidade dos processos de desnaturalização em rios e bacias hidrográficas urbanas. Revista do Departamento de Geografia, 40, 163-174.

Castro, E. R.(2016). Efeitos ambientais na distribuição de insetos aquáticos (Ephemeroptera, Plecoptera e Trichoptera) em tributários do rio Itapecuru, no Leste Maranhense.

Companhia de Desenvolvimento dos Vales do São Francisco e do Parnaíba - CODEVASF. (2019). Plano Nascente Itapecuru: plano de preservação e recuperação de nascentes da bacia hidrográfica do rio Itapecuru.

Correia Filho, F. L., Gomes, É. R., Nunes, O. O. \& Lopes Filho, J. B. (2011). Projeto cadastro de fontes de abastecimento por água subterrânea: estado do Maranhão: relatório diagnóstico do município de Caxias. CPRM.

Costa, A. F. S., Teixeira, C. M., Silva, C. S., Nascimento, J. A., Oliveira, M. M., Oliveira Queiroz, Y. \& de Jesus Silva, M. (2012). Recursos hídricos. Caderno de Graduação-Ciências Exatas e Tecnológicas-UNIT-SERGIPE, 1(1), 67-73.

Dellamatrice, P. M., \& Monteiro, R. T. (2014). Principais aspectos da poluição de rios brasileiros por pesticidas. Revista Brasileira de Engenharia Agrícola e Ambiental, 18, 1296-1301.

Feio, M. J. \& Teixeira, Z. (2019). Alterações globais dos rios: pressões antropogênicas e alterações climáticas. Imprensa da Universidade de Coimbra: Coimbra, Portugal.

Feitosa, A. C., \& Almeida, E. D. (2002). A degradação ambiental do rio Itapecuru na sede do município de Codó-MA. Cad. Pesq., 13(1), 31-45.

Ferro, W. C., Macedo Silva, G. N., Silva, J. S., \& Veras, D. S. (2018). Percepção ambiental dos moradores ribeirinhos sobre a ocorrência dos impactos ambientais na margem direita do rio Itapecuru, na avenida beira rio em Caxias-MA.

Galvão Junior, A. C., Custódio, A. M. B., \& Duarte, C. S. (2018). Acesso à água nas regiões norte e nordeste do brasil: desafios e perspectivas. Instituto Trata Brasil. Recuperado de http://tratabrasil.org. br/images/estudos/acesso-agua/tratabrasil_relatorio_v3_A. pdf.

Gaspar, J. \& Conceição, G. (2017). Parâmetros e indicadores da qualidade da água no riacho do ouro, Caxias, Maranhão. Enciclopédia Biosfera, 14(25).

Gomes, M.R. (2019). Avaliação da qualidade da água de distribuição em alguns municípios do estado do Ceará.

Instituto Brasileiro de Geografia e Estatística-IBGE. (2021). Censo 2020. https://cidades. ibge.gov.br/brasil/ma/caxias/panorama

Instituto Maranhense de Estudos Socioeconômicos Cartográficos-IMESC (2019). Relatório Técnico de Limnologia do Zoneamento Ecológico Econômico do Estado do Maranhão.

Jesus Silva, D., \& Conceição, G. M. (2011). Rio Itapecuru: caracterização Geoambiental e socioambiental, município de Caxias, Maranhão, Brasil. Scientia Plena, 7(1).

Libâneo, M. (2010). Fundamentos de qualidade e tratamento de água. Átomo.

Martins, R.A. (2019). Qualidade da água do baixo curso do rio Itapecuru e como fundamento na saúde humana e usos múltiplos.

Masullo, Y., Soares, L., Castro, C., \& Pinheiro, E. (2019). Dinâmica da paisagem da bacia hidrográfica do rio Itapecuru - MA. Revista Brasileira de Geografia Física, 12(3), 1054-1073. doi:https://doi.org/10.26848/rbgf.v12.3.p1054-1073

Medeiros, W. M. V., Silva, C. E. D., \& Lins, R. P. M. (2018). Avaliação sazonal e espacial da qualidade das águas superficiais da bacia hidrográfica do rio Longá, Piauí, Brasil. Revista Ambiente \& Água, 13.

Mello, F. D. A., \& Olivo, A. D. M. (2016). Recursos Hídricos: poluição, escassez, qualidade microbiológica e química da água. In Colloquium Vitae (Vol. 8, pp. 36-42).

Nogueira, F. F., Costa, I. A., \& Pereira, U. A. (2015). Análise de parâmetros físico-químicos da água e do uso e ocupação do solo na sub-bacia do Córrego da Água Branca no município de Nerópolis-Goiás. Monografia Bacharelado em Engenharia Ambiental e Sanitária. Universidade Federal de Goiás, (Goiânia).

Núcleo Geoambiental-NUGEO. (2016). Bacias hidrográficas e climatologia no Maranhão.

Pereira, P. B., Brito Nunes, H. K., \& Silva Araújo, F. D. A. (2021). Análise multitemporal de uso, ocupação e cobertura da terra na zona Leste da cidade de Caxias/Maranhão/Brasil. Revista Brasileira de Geografia Física, 14(03), 1415-1428.

Queiroz Ribeiro, D., Chagas, A. D. J. F., Silva, D. S., \& Barreto, H. N. (2019). Demandas hídricas consuntivas na unidade de planejamento hídrico do rio Itapecuru-Maranhão. Revista da Casa da Geografia de Sobral (RCGS), 21(2), 348-363.

Ridder Vieira, A., Costa, L., \& Barrêto, S. R. (2006). Água para Todos: Livro das Águas. 
Rosário, M. B. S. S., Lima, T. C., \& Brito Nunes, H. K. (2020). Entre morros e olhares: a percepção ambiental de moradores frente aos riscos de deslizamentos em bairros de Caxias/MA.Terr@ Plural, 14, 1-18.

Saneamento, M. (2018). Fundação Nacional de Saúde. Ministério da Saúde. Departamento de Saneamento.

Santos, L. D., \& Leal, A. (2010). Política de recursos hídricos no estado do Maranhão. As novas geografias dos países de língua portuguesa: paisagens, territórios, políticas no Brasil e Portugal. Guarda: CEI.

Silva Pereira, C., Rodrigues, M. O. S., Santos Barros, C. L., Almeida, B. L. N., \& Andrade Diogo, M. L. S. (2020). Identificação de impactos ambientais provocados pelo lançamento de resíduos sólidos e líquidos no rio Itapecuru. Nature and Conservation, 13(2), 58-66.

Silva Pereira, R.(2004). Poluição hídrica: causas e consequências.

Silva, A. B., Silva, J. D. C., De Melo, B. F., Do Nascimento, R. F., Duarte, J. D. S., \& Da Silva Filho, E. D. (2019). Análise microbiológica da água de bebedouros nas escolas públicas da cidade de Esperança/PB. South American Journal of Basic Education, Technical and Technological, 6(1).

Silva, F. P., Alencar Carvalho, C. V., \& Cardoso, A. M. (2019). Gestão da água: A importância de políticas públicas para a implementação do reuso de água no Brasil. Episteme Transversalis, 10(2).

Silva, R. N. M., Silva, D. L. L., Ferreira, G. B., Costa, Z. J. S., Silva, D. L.S., Sousa, R.N.S., Pereira, L.P.L.A., Rego, P.F.F., Martins, B.N., Almeida, N.M. \& Nascimento Sírio, D. L. (2017.) Caracterização Preliminar da Bacia Hidrográfica do rio Itapecuru. XX Simpósio Brasileiro de Recursos Hídricos.

Silva, T. A. S. (2017). Avaliação da qualidade da água nas escolas no município de Formiga-MG.

Sodré, F. F. (2012). Fontes difusas de poluição da água: Características e métodos de controle. Agricultura, 1(2o), 3o.

Souza Junior, E. G., \& Oliveira, V. D. P. S. (2016). Qualidade da água do rio Itabapoana: Análise dos parâmetros físico-químicos e microbiológicos e influência de empreendimentos hidrelétricos.

Souza, J. R., Moraes, M. E. B., Sonoda, S. L., \& Santos, H. C. R. G. (2014). A importância da qualidade da água e os seus múltiplos usos: caso rio Almada, sul da Bahia, Brasil. REDE-Revista Eletrônica do Prodema, 8(1).

Tardoque, D. W. D. A. (2021). Análise microbiológica da água do instituto de saúde de Nova Friburgo da Universidade Federal Fluminense.

Tucci, C. E., Hespanhol, I., \& Cordeiro Netto, O. D. M. (2001). Gestão da água no Brasil.

Tundisi, J. G. (2014). Recursos hídricos no Brasil: problemas, desafios e estratégias para o futuro. Rio de Janeiro: Academia Brasileira de Ciências, 76.

Venancio, D., Santos, R., Cassaro, S., \& Pierro, P. (2015). A crise hídrica e sua contextualização mundial. Enciclopédia Biosfera, 11(22).

Von Sperling, M. (2005). Introdução à qualidade das águas e ao tratamento de esgotos (Ed. 3). Editora UFMG. 